\title{
ASPECTOS SOCIOECONÔMICOS DAS ASSOCIAÇÕES DA COLÔNIA DE PESCADORES E AQUICULTORES DO MUNICÍPIO DE APODI - RN
}

\author{
S. D. P. VALE ${ }^{1}$, F.R. $\operatorname{COSTA}{ }^{2, *}$ \\ ${ }_{1,2}$ Universidade do Estado do Rio Grande do Norte, Campus Pau dos Ferros \\ franklincosta@uern.br
}

Submetido 05/04/20x16 - Aceito 28/09/2018

DOI: 10.15628/holos.2018.2932

\section{RESUMO}

O trabalho teve como objetivo analisar as manifestações que ocorrem no espaço geográfico decorrente da atividade pesqueira das associações de pescadores e aquicultores do município de Apodi, visando conhecer as condições de vida e de trabalho e montar um perfil socioeconômico de 35 famílias de pescadores. Para isso, foram utilizados dados de caráter primário e secundário para a obtenção de informações que nos nortearam no decorrer do estudo. Em um primeiro momento, a pesquisa constitui um breve histórico sobre a pesca e as colônias de pescadores no país e a influência destas nas comunidades tradicionais. Em um segundo momento, há a caracterização da área estudada, seguida pela discussão dos resultados obtidos, analisando e caracterizando a área pesquisada e 0 perfil socioeconômico dos pescadores do município. Os fatores analisados apontaram para uma intensificação dos problemas sociais e econômicos vividos e percebidos pelos pescadores. Mas por outro lado, a permanência e persistência dos pescadores em darem continuidade à atividade pesqueira, mesmo em pequena escala, apontam para a necessidade de garantir o uso múltiplo dos recursos naturais do município.

PALAVRAS-CHAVE: pescadores, socioeconomia, colônia de pescadores, reservatório.

\section{SOCIO-ECONOMIC ASPECTS OF ASSOCIATIONS FISHERMEN AND AQUICULTURAL COLONIES IN MUNICIPALITY OF APODI - RN}

\begin{abstract}
The work aimed to analyze the events that occur in the geographical space resulting from the fishing activity of associations of fishermen and fish farmers of the municipality of Apodi, aiming to meet living and working conditions and mount a socioeconomic profile of 35 families of fishermen. For this, we used primary and secondary data for obtaining information that guided us in the course of the study. In a first moment the research constitutes a brief history on fishing and fishermen's colonies in the country and the influence of traditional communities. In a second moment for the
\end{abstract}

characterization of the study area followed by discussion of the results obtained by analyzing and characterizing the area searched and the socioeconomic profile of anglers in the municipality. The factors analyzed pointed to an intensification of the social and economic problems experienced and perceived by fishermen. But on the other hand, the permanence and persistence of in giving continuity to the fishing activity, even on a small scale, point to the need to ensure the multiple use of natural resources in the County.

KEYWORDS: fishermen, socioeconomy, fishermen colony, water reservoirs. 


\section{INTRODUÇÃO}

Discutir o significado da Geografia e do seu objeto de estudo não é uma tarefa simples. Durante a evolução do pensamento geográfico, diversos teóricos empreenderam tal jornada, valorizando primeiramente, a definição da Geografia e, mais tarde, a do seu objeto (Santos, 2008). Assim, pode-se afirmar que a Geografia é uma ciência das práticas e saberes sociais que se dedica a analisar e compreender as relações estabelecidas entre o homem e a natureza em sua organização espacial e na produção do espaço (Moreira, 2017).

No caso dessa pesquisa, o espaço a ser considerado é o social e, nesse sentido, se apresenta como algo que se impõe a tudo e a todos, que tem o poder de conter e ser contido por instâncias, como a econômica e a ideológica-cultural. Diante disso, pode-se afirmar que existem diversas formas de interação que surgem a partir da própria construção social, de cada indivíduo e localidade, com diferentes visões acerca de como o homem percebe o meio, necessitando, nesse caso, de análises interdisciplinares em diferentes interfaces (Cidreira Neto \& Rodrigues, 2017).

A atividade de pesca, sendo uma destas perspectivas, já existe há milênios e está presente desde as primeiras organizações humanas (Secretaria de Estado da Pesca e da Agricultura do Estado do Pará [SEPAQ] 2010). Ao passo que o mundo se modernizava, a população ocupava novos espaços e essa atividade ganhou importância econômica, pois serviu como fonte de subsistência para muitas famílias de baixo poder aquisitivo (Cardoso, Furlan, Martins, Kemel, 2009).

No Brasil, as organizações de pescadores estão ganhando cada vez mais força, tendo como objetivo representar e defender os interesses dos pescadores perante os órgãos públicos. É através dessas instituições que os pescadores ganham reconhecimento enquanto sujeito-social e como principal protagonista do modelo de gestão da categoria (Moura, Loureiro, Anello, 2016).

No município de Apodi, localizado no estado do Rio Grande do Norte, a iniciativa de um grupo de pescadores em implantar um projeto de criação de tilápias na barragem de Santa Cruz começou a se destacar na região conhecida como Vale do Apodi. O projeto desenvolvido na região deu novo impulso à piscicultura do município e uma nova forma de vida à população. Mas, é importante lembrar que muitas dessas comunidades, que dependem da produção e comercialização de pescado como meio fundamental de renda e alimentação, estão submetidas a situações de pobreza, riscos sociais e ambientais (SEPAQ, 2010). E diante da escassez de dados referentes ao aspecto socioeconômico dessas entidades e dos seus membros, segundo Gonçalves (2006), torna-se justo e notável um estudo aprofundado sobre as manifestações que ocorrem no espaço geográfico decorrente da atividade pesqueira.

A perspectiva geográfica de compreender a pesca e os pescadores permite ampliar o foco da análise e incorporar novas dimensões da construção do espaço a partir dessa prática. Por isso, essa pesquisa teve como objetivo analisar as manifestações que ocorrem no espaço geográfico decorrente da atividade pesqueira das associações de 
pescadores e aquicultores do município de Apodi, visando conhecer as condições de vida e de trabalho e montar um perfil socioeconômico de 35 famílias de pescadores.

Para isso, foram usados dados de caráter primário e secundários para a obtenção de informações empíricas que nos nortearam no decorrer do estudo, e para nos integrar da realidade vivida pelos moradores dependentes da Colônia, procurou-se analisar suas limitações, seus métodos de trabalho, sua renda e seu modo de vida, visando a partir dos dados obtidos, contribuir para a criação de um banco de dados sobre a mesma, visto que esse se encontra inexistente.

\section{REVISÃO BIBLIOGRÁFICA}

\subsection{Setor pesqueiro no Brasil}

O histórico referente ao desenvolvimento da pesca no Brasil começou no início do século XX com a formação do Estado nacional e com o estabelecimento da marinha de guerra brasileira (Silva, 1991). Com o intuito de diminuir as importações de pescado, torná-la auto-sustentável e defender a costa o governo, juntamente com a Marinha do Brasil, desenvolveu sistemas de organização da categoria pesqueira criando as primeiras colônias, federações e confederações brasileiras de pescadores.

$\mathrm{Na}$ tentativa de simplificar a diversidade de situações presentes na realidade da pesca, Diegues (1983) subdivide a pesca em dois setores: empresarial e artesanal. O primeiro caracteriza-se por ser uma atividade desenvolvida por empresas pesqueiras com alto nível de integração com os setores de captura, processamento e comércio dos produtos. Já a pesca artesanal, é realizada dentro dos moldes da produção mercantil e exercida por produtores autônomos, ou com relações de trabalho em parceria, que utilizam pequena quantia de capital e meio de produção simples, com tecnologias e metodologias de captura não mecanizada e baseada em conhecimentos empíricos (SEPAQ, 2010).

O Brasil ocupava a $13^{a}$ posição, até 2009 , entre os maiores produtores de pescado do mundo (Brasil, 2012). Esse padrão se manteve devido à grande contribuição dos pescadores artesanais e da aquicultura. Os primeiros contribuíram com $68,3 \%$ da pesca nacional, produzindo cerca de 536.455 mil toneladas para o ano de 2010 no Brasil (Brasil, 2012). Já a aquicultura, de acordo com Pinheiro (2003), se define como a criação de pescado em tanques-rede ou em gaiolas em quantidade controlada e com o uso de ração para alimentar a criação. Segundo o Serviço Brasileiro de Apoio às Micro e Pequenas Empresas - SEBRAE (2008) essa atividade é praticada há milênios, provavelmente pelas civilizações do Oriente no século $V$ a.C. Atualmente é o meio de subsistência que tem elevado valores sociais às comunidades dos países subdesenvolvidos e em desenvolvimento, uma vez que é uma alternativa de renda para pescadores e agricultores.

Ainda segundo o SEBRAE (2008), o Brasil possui um grande potencial para o desenvolvimento sustentável dessa atividade, devido ao seu enorme potencial hídrico, clima favorável, mão-de-obra, e crescente demanda por pescado nos mercados internos 
e externos. Além desses pontos, pesa no setor aquícola o fato de que a pesca extrativista atingiu os seus limites máximos sustentáveis de captura nos últimos anos, e não consegue mais atender a demanda mundial e com isso essa prática passou a ser cada vez mais incentivada. No Brasil, essa atividade transpõe o patamar de 270 mil toneladas, passando a contribuir com $25,9 \%$ da produção total do país (Secretaria Especial de Aquicultura e Pesca [SEAP], 2007), sendo a Região Nordeste responsável por produzir 10\% desse pescado (Instituto UNIEMP, 2010).

De acordo com a EMBRAPA (2017), as espécies mais comuns produzidas no país, por região são: tambaqui, pacu e pintado (Centro-Oeste); tilápia e camarão marinho (Nordeste); tilápia, pacu e pintado (Sudeste); carpa, tilápia, jundiá, ostra e mexilhão (Sul).

O RN reúne todas as características para o desenvolvimento da aquicultura e pesca por meio da exploração dos seus sistemas marinho, lacustres, estuários e, principalmente em águas interiores na região do semi-árido, embora a pesca marinha ainda apresente prioridade nas ações políticas e estratégicas na esfera governamental. Isso ocorre principalmente pelos costumes e tradições do estado que possui características e vocação para a exploração de recursos oriundos do mar (Queiroz \& Moura, 1996).

\subsection{A pesca e as colônias de pescadores}

A atividade pesqueira no interior do estado ganha importância econômica e social à medida que um elevado contingente de trabalhadores tem na pesca e nas atividades ligadas ao setor, sua principal fonte de renda, alimentação e é responsável por um elevado nível de empregos nas comunidades interioranas, sendo também importante na manutenção da grande diversidade cultural que está vinculada às atividades desenvolvidas pelos pequenos pescadores (Cardoso, 2007). Como afirma Diegues (2000), o território é um dos elementos mais significativos na relação entre as comunidades "tradicionais" e a natureza.

Ao longo dos anos, com a mecanização dos recursos pesqueiros, o pescador artesanal enfrentou diversos desafios com relação à luta constante pelos seus espaços de vida, trabalho e moradia. Aos poucos foram ganhando importância enquanto sujeitosocial, político e agente principal de um modelo de gestão das pescarias. Como entidades, atuam no cadastramento dos pescadores orientando-os na questão de segurança social e na preservação dos recursos naturais (Silva, 2009).

Segundo Costa (2003), essas associações são antigas no Nordeste brasileiro, e nos últimos anos ganharam importância sindical. Mas perderam suas características essenciais que é defender e representar os pescadores, devido a diversas razões. Entre elas podem ser citados os dirigentes que se afastam da comunidade, e o desvio e o mau uso de verbas públicas e da receita da colônia.

Em estudos desenvolvidos sobre a cadeia produtiva da pesca artesanal do estado do Pará, Santos (2005) também reforça essas estimativas e diz que há uma extrema precariedade de infra-estrutura para funcionamento e execução de atividades nessas 
colônias, devido à inadimplência de grande número dos associados e, principalmente, as dificuldades de mobilização dos pescadores para reuniões e eventos de outra natureza.

Essas populações que dependem da produção e comercialização de pescado, muitas vezes estão submetidas a situações de pobreza, riscos sociais e ambientais (SEPAQ, 2010). Esses grupos, muitas vezes refletem um perfil socioeconômico com características ligadas ao baixo nível educacional, baixo poder aquisitivo, e a situações precárias de trabalho. Por isso, segundo Gonçalves (2006), torna-se justo e notável um estudo aprofundado sobre as manifestações que ocorrem no espaço geográfico decorrente da atividade pesqueira, para que ocorra a elaboração de planos locais de gerenciamento pesqueiro que considerem todos os atores e interesses envolvidos, principalmente aqueles das comunidades tradicionais que dependem exclusivamente do recurso, buscando a sustentabilidade de forma socialmente justa e ecologicamente viável (Diegues, 1996).

\section{MATERIAIS E MÉTODOS}

\section{1 Área de estudo}

A área de estudo dessa pesquisa compreende a Colônia de Pescadores e Aquicultores do município de Apodi-RN, localizado na mesorregião do Oeste Potiguar. A colônia localiza-se às margens da barragem de Santa Cruz, considerada o segundo maior reservatório do estado. E está localizada na Bacia do Apodi-Mossoró, no boqueirão denominado Santa Cruz.

Segundo dados o Instituto Brasileiro de Geografia e Estatística-IBGE, a barragem foi projetada e construída pelo Departamento Nacional de Obras Contra as Secas DNOCS e teve a sua inauguração no dia 11 de março de 2002, pelo Presidente Fernando Henrique Cardoso e por Garibaldi Alves Filho, Governador do Rio Grande do Norte naquele período.

A colônia de pescadores $Z$ - 48 foi fundada no dia 04 de maio de 2001, por iniciativa de um grupo de pescadores locais que reivindicavam melhores condições de vida e de trabalho aos órgãos públicos. Com o apoio do Serviço Social da Indústria SESI, o conselho comunitário do bairro Malvinas na cidade de Apodi, conseguiu a autorização judicial para a fundação da sede na Comunidade de Santa Cruz II, no município.

A Colônia de Pescadores e Aquicultores de Apodi tem seus objetivos voltados para o estudo, à defesa e a coordenação das categorias de trabalhadores que fazem da pesca e aquicultura sua profissão, ou seu principal meio de vida. São prerrogativas da colônia, representar perante autoridades administrativas e/ou judiciárias, os interesses gerais da categoria, informar, reclamar ou denunciar qualquer assunto que diga respeito ao meio ambiente ou aos demais aspectos referentes à pesca. São funções da Colônia Z - 48, promover atividades de educação profissional visando à formação, qualificação e requalificação do pescador juntamente as parcerias públicas e privadas. 
A parte administrativa é formada por seis membros: Presidente, Vice-presidente, Secretário, segundo Secretário, Tesoureiro e segundo Tesoureiro. Para cadastrar-se na entidade são necessários documentos pessoais e ter experiência com atividade pesqueira, seja ela amadora ou profissional. Na Colônia existem três categorias de associados: os sócios efetivos, ou seja, os pescadores ou pescadoras profissionais, pequenos armadores de pesca, artesãos e artesãs de pesca e pequenos fabricantes de embarcações e aquicultores em geral; os sócios cooperadores, que pode ser qualquer cidadão que deseje contribuir para o desenvolvimento do espirito associativo da categoria. E também os sócios honorários, que são os pescadores que têm título agraciado em assembleias gerais de colônias.

A Colônia de pescadores e Aquicultores é constituída por duas associações, a Associação dos Pescadores do Apodi - AQUAPO, fundada em 2007 sem fins lucrativos com sede na comunidade de Santa Cruz II no município de Apodi - RN e a Associação de Pescadores e Aquicultores Familiar de Apodi - APAFA, fundada em 18 de outubro de 2009 com sede no sitio Melancias II, zona rural do município. Ambas com os objetivos voltados para prestação de qualquer serviço que possa contribuir para o fomento e racionalização das atividades de pesca e aquicultura, assim como a defesa das atividades econômicas, sociais e culturais de seus associados.

Nas duas associações, o protocolo de cadastramento segue a mesma linhagem, sendo necessários os documentos pessoais e experiências com a pesca artesanal ou em cativeiro. Para associar-se, todos os membros devem concordar com as disposições dos estatutos que regem as normas da colônia e se comprometer a contribuir para a consecução dos objetivos da sociedade. A exclusão dos mesmos ocorre por morte física, por incapacidade civil não suprida, ou ainda por deixar de atender aos requisitos exigidos para a sua admissão ou permanência nas associações.

As associações mantêm parcerias com órgãos públicos como o Serviço Brasileiro de Apoio às micros e pequenas empresas - SEBRAE, que contribui com cursos de capacitação e recapacitação dos associados; a CONAB - Companhia Nacional de Abastecimento que faz a compra e revenda do pescado; a Marinha do Brasil com cursos de segurança na água; a Empresa de Pesquisa Agropecuária do RN - EMPARN, que promove o desenvolvimento rural; a profissionalização e a difusão das tecnologias para o setor; a Confederação Nacional dos Pescadores e Aquicultores - CNPA, contribuindo para a elaboração de propostas de gestão para o setor; o Instituto de Desenvolvimento Sustentável e Meio Ambiente - IDEMA - RN, que tem a missão de promover Políticas Ambientais para o Estado; visando o desenvolvimento sustentável em busca da melhoria da qualidade de vida da população; o Departamento Nacional de Obras contra a Seca DNOCS e o Instituto Brasileiro do Meio Ambiente e dos Recursos Naturais Renováveis IBAMA.

Todas essas instituições têm o dever de contribuir com cursos de capacitação, auxílios técnicos, sociais e fiscalização, para que haja um aumento e melhoria da produtividade. 


\subsection{Processos metodológicos}

Os dados que foram usados nesta pesquisa são de caráter primário e secundário. Os dados primários referem-se às entrevistas e questionários aplicados aos pescadores, aos Presidentes das Cooperativas e as famílias associadas. Os dados secundários referem-se às informações obtidas no levantamento bibliográfico e documental.

Fevereiro e março de 2011 foram dedicados ao levantamento e seleção das bibliografias. Seguido das visitas realizadas no fim do mês de março e início de abril às Associações e as residências dos pescadores, a fim de reconhecer a área de estudo e identificar as "pessoas chave" que atuam no reservatório Santa Cruz.

Com o intuito de diagnosticar os impactos da atividade pesqueira sobre os membros da Colônia de pescadores e aquicultores de Apodi se fez necessário caracterizar o contexto Socioeconômico das famílias associadas à cooperativa. Para isso foram realizadas entrevistas com 35 famílias das 45 que estão trabalhando atualmente no projeto. Cada entrevista continha perguntas referente à idade, escolaridade, renda mensal, condições de moradia, número de filhos, estado civil, além de dados técnicos como, os instrumentos usados na atividade pesqueira, a espécie de peixe explorado, a administração das associações e da colônia em si e também perguntas subjetivas referentes às dificuldades enfrentadas por esses moradores e suas perspectivas de melhoria para o setor.

Também foram entrevistados os presidentes das cooperativas AQUAPO (Associação de aquicultores de Apodi), APAFA (Associação de Aquicultores familiar de Apodi) e da Colônia, a fim de obter dados da própria cooperativa como o perfil dos pescadores e do local de estudo, os históricos, questões financeiras, institucionais, dados sobre o cultivo tais como, conflitos de uso, aspectos tecnológicos e as relações dessas com outras instituições.

Em maio de 2011 houve a organização quantitativa e qualitativa dos dados da fase exploratória e da aplicação dos questionários em gráficos e dados percentuais discutidos nos resultados. Em junho do mesmo ano, iniciou-se a análise e discussão das amostras, utilizando o método Descritivo-interpretativo para a construção do produto final.

\section{RESULTADOS E DISCUSSÕES}

\subsection{Atividade pesqueira do Município de Apodi - RN}

A pesca no município de Apodi é caracterizada como atividade praticada por uma parcela da população que encontra nessa prática os meios de subsitência.

Estão associados à Colônia de Apodi 600 pescadores, cadastrados legalmente e usufruindo dos direitos oferecidos pela carteira de pescador. Nas associações estão registradas cerca de 45 famílias, que fazem da atividade pesqueira sua principal fonte de renda. Tanto na AQUAPO quanto na APAFA, são praticadas a pesca e a aquicultura. Os sistemas de trabalho são divididos em cotas-parte, onde se divide todo o lucro e as despesas de forma igualitária, desde os Presidentes das associações até o lavador de gaiolas. (Figura 01) 
Durante as entrevistas questionou-se sobre os instrumentos de trabalho, e 28 dos 35 entrevistados, responderam que a atividade é realizada exclusivamente na unidade de criação e que utilizam materiais como canoas, tanques-rede, pulsares, medidores de temperatura, freezers, caixas térmicas e balanças.

Figura 01: Unidade

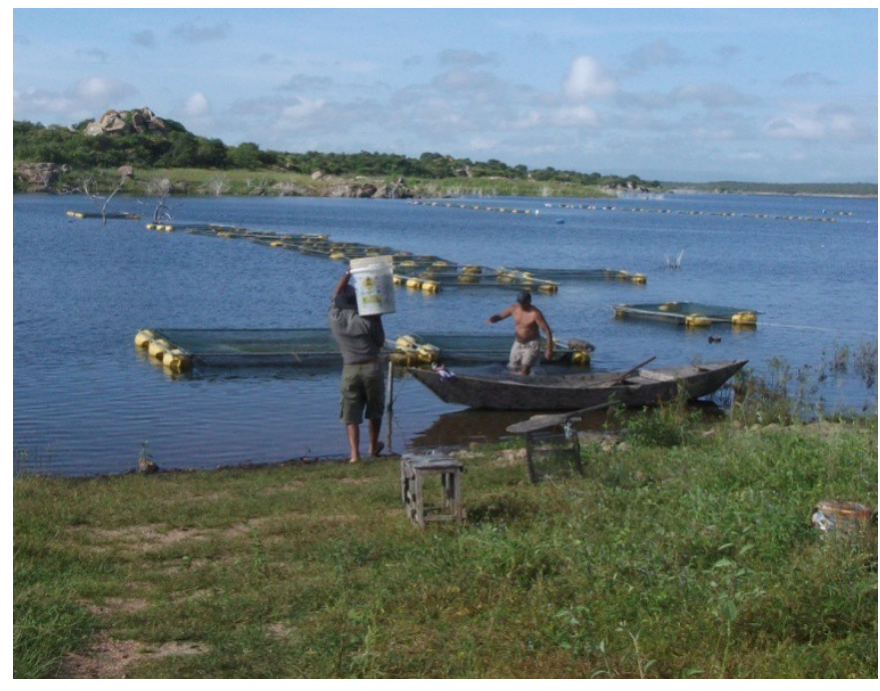

criação de tilápias em cativeiro-Barragem de Santa Cruz.

Fonte: Vale, 2011. demonstrativa de

As tarefas também são divididas igualmente entre os membros, sendo que a cada dia 2 pescadores de cada grupo são responsáveis pela alimentação dos alevinos, limpeza das gaiolas, manutenção do local de trabalho e distribuição da mercadoria, alguns pescadores são responsáveis apenas pela captura artesanal do pescado.

A principal espécie de peixe criada e pescada pelas cooperativas é a Tilápiasrendali (Oreochrominiloticus) (FIGURA 02).

Figura 02: Tilápias-

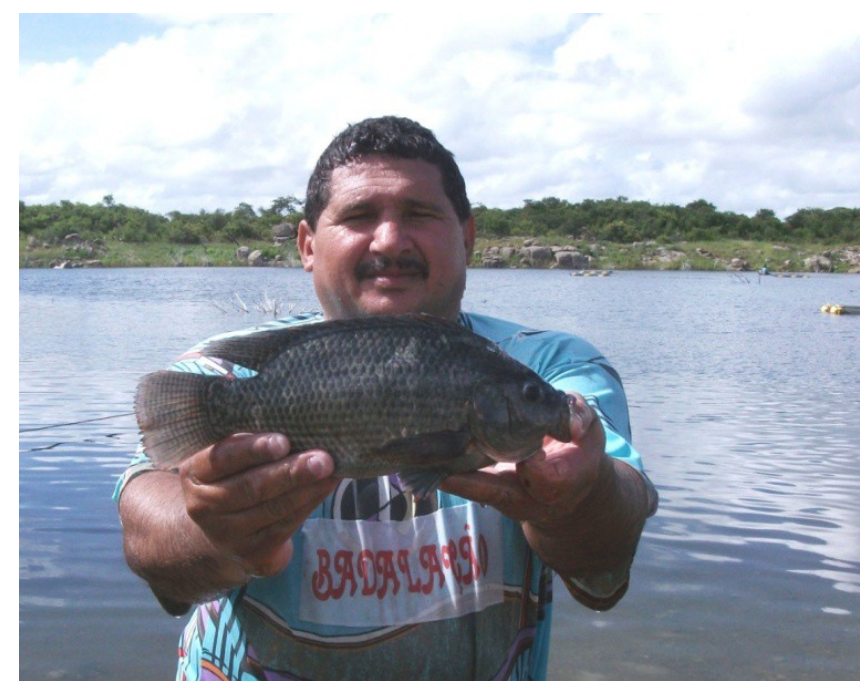

Fonte: Vale, 2011. rendali.

O sistema de criação é feito, inicialmente, a partir da compra dos alevinos realizada no interior da Paraíba e em Natal-RN, custando em média, $R \$ 100,00$ (cem 
reais) a cada 1000 alevinos. Depois de transportados em pequenas embarcações a remo com capacidade para 4 pessoas, são colocados nas gaiolas de pequeno porte, passam 30 dias ganhando forma, e posteriormente são transferidos para os tanquesrede, com capacidade para 1500 peixes, onde são alimentados e crescem em um período de 5 meses. Quando chegam ao peso ideal, 3 a 4 pescadores entram nas gaiolas e começam a retirada (FIGURA 03).

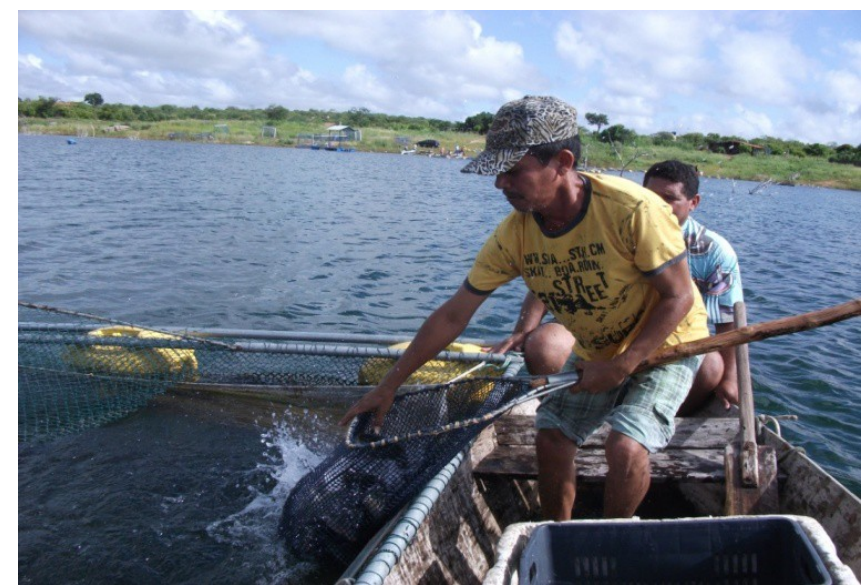

Figura 03: retirada do pescado das gaiolas de criação. Fonte: Vale, 2011.

A produção semestral desse pescado varia de 12 a 15 toneladas, e é comercializado a partir da Companhia Nacional de Abastecimento - CONAB, responsável pela compra da maior parte da mercadoria. Essa instituição vende uma média de $1.120 \mathrm{~kg}$ do produto por entrega, para cerca de 2.160 famílias mensalmente. $\mathrm{O}$ restante é vendido no mercado local pelo preço de 6,00 $\mathrm{R} \$$ o $\mathrm{kg}$. O pescado é vendido na forma de filé, inteiro, eviscerado e sem a cabeça. O tratamento e preparo são feitos nas próprias sedes das associações, valendo salientar que durante as visitas aos locais de trabalho e desembarque não foram detectados locais apropriados para esse tipo de processo, o que revela a falta de infraestrutura (FIGURA 04).

Figura 04: Sede da

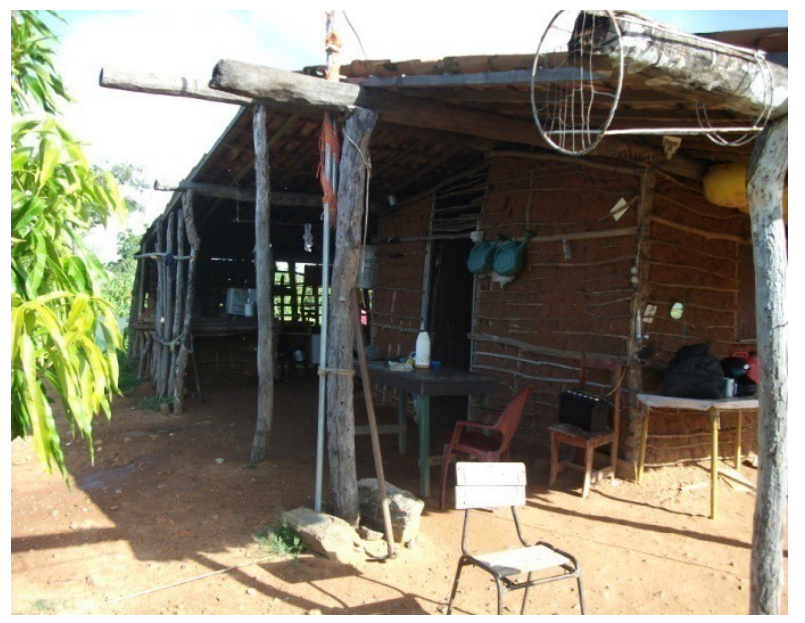

Fonte: Vale, 2011.
AQUAPO. 
A cadeia intermediária do pescado talvez seja uma das mais longas do setor primário. Aliando-se ao fato da alta perecibilidade do pescado enquanto mercadoria, estes fatores resultam em uma transferência de renda do pescador para os setores de distribuição e comercialização do pescado. A inconstância das capturas compromete também os rendimentos dos pescadores, visto que, os lucros variam de acordo com a produtividade, rendendo atualmente no município menos de um salário mínimo por pessoa mensalmente (Cardoso, 2007).

A pesca é realizada durante todo o ano, exceto no período de Piracema, onde há a reprodução das espécies nos meses de janeiro a abril. Durante esse tempo, os pescadores profissionais cadastrados há mais de um ano no Ministério da Pesca, dizem recorrer à documentação que lhes garantem o seguro Defeso. O beneficio é de um salário mínimo, pago pelo Ministério do Trabalho e Emprego (MTE).

Desde novembro de 2009, pescadores e pescadoras com carteira definitiva estão incluídos na relação dos seguros especiais do Instituto Nacional de Seguros Sociais (INSS). Eles têm direitos ao auxílio-doença, salário-maternidade, aposentadoria por invalidez por idade, e pensão por morte para a família. A nova lei da pesca, número $11.959 / 09$, reconhece os pescadores artesanais e aquicultores como produtores rurais, com direitos aos mesmos benefícios dos agricultores na Previdência Social e linhas de crédito especial do Programa Nacional de Fortalecimento à Agricultura Familiar PRONAF (MPA, 2010). Durante o levantamento, foram feitas perguntas sobre os benefícios da carteira de pescador, e 26 pescadores desconhecem parte desses benefícios. Os 9 restantes, disseram conhecer os benefícios, mas não utilizam.

\subsection{Perfil socioeconômico dos pescadores}

É notória a precariedade das estatísticas da pesca em todo o Brasil. O país sofre de uma carência de informações socioeconômicas sobre o pescador artesanal, assim como os seus métodos de produção e condições de trabalho. Por isso, esse trabalho visa fortalecer esse banco de dados através da pesquisa socioeconômica feita com alguns pescadores do município de Apodi.

Foram entrevistados 35 pescadores registrados nas Associações de Pescadores AQUAPO e APAFA. 23 são homens e 13 são mulheres, com idades que variam de 19 a 60 anos. Dados coletados, em 2002, pelo Ministério do Trabalho no programa de seguro desemprego no Brasil mostram que entre os pescadores do sexo masculino, somente $13,0 \%$ deles têm menos de 30 anos de idade e, entre as mulheres, 13,6\%, o que revela a dificuldade atual encontrada pela pesca artesanal em despertar o interesse dos mais jovens para essa atividade (Vasconcellos et al. 2007).

O tempo de trabalho divulgado pela maioria dos pescadores é de pelo menos 20 anos de profissão, sendo importante salientar que o registro de pescador só foi concedido a esses pescadores depois da fundação da Colônia no Município.

Com relação ao estado civil, as entrevistas detectaram que 24 pescadores são casados e possuem família constituída, 9 deles se declararam solteiros, separados ou viúvos. Em 18 residências há uma média de 0 a 2 filhos por família, o que provavelmente esta ligado a parcela mais jovem de pescadores, o número de pessoas que disseram ter mais de 3 filhos atingiu um média de $49 \%$ como mostra o gráfico da figura 05. 


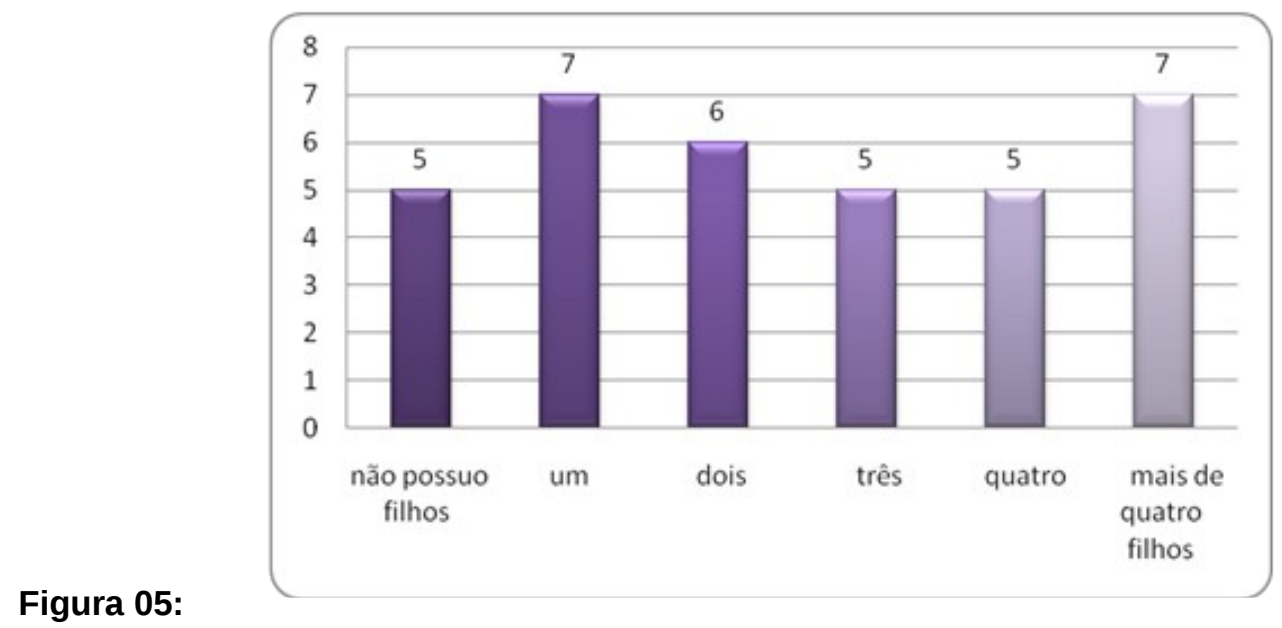

Gráfico do número

de filhos por família das associações AQUAPO e APAFA.

Esses dados podem ser explicados, pela baixa escolaridade de uma parcela pobre da população e as precárias condições de vida que contribui para a ampliação desses fatores. Diante de dados como esses, vale salientar também que o Brasil sofreu uma positiva mudança nos seus indicadores sociais nas últimas décadas. O tamanho das famílias brasileiras, por exemplo, na década de 80 era de 4,5 pessoas em média, chegando ao fim dos anos 90 com apenas 3,4 pessoas. As famílias tradicionais, compostas pelo casal com filhos, caíram de quase 60\%, em 1992, para 55\%, em 1999, ao mesmo tempo em que aumentou a proporção de outros tipos de composição familiar. A redução do tamanho da família pode ser explicada, sobretudo, pela acentuada queda na taxa de fecundidade nas últimas três décadas, de 5,8 filhos, em 1970, chega a 1999 com 2,3 filhos. Fatores como a mudança de valores culturais do brasileiro e o ingresso maciço de mulheres no mercado de trabalho também influenciaram a redução da família ao núcleo conjugal com filhos (IBGE, 2010).

A renda também é um fator determinante no tamanho das famílias, sendo o número de filhos e de pessoas inversamente proporcional à renda familiar (FIGURA 06).

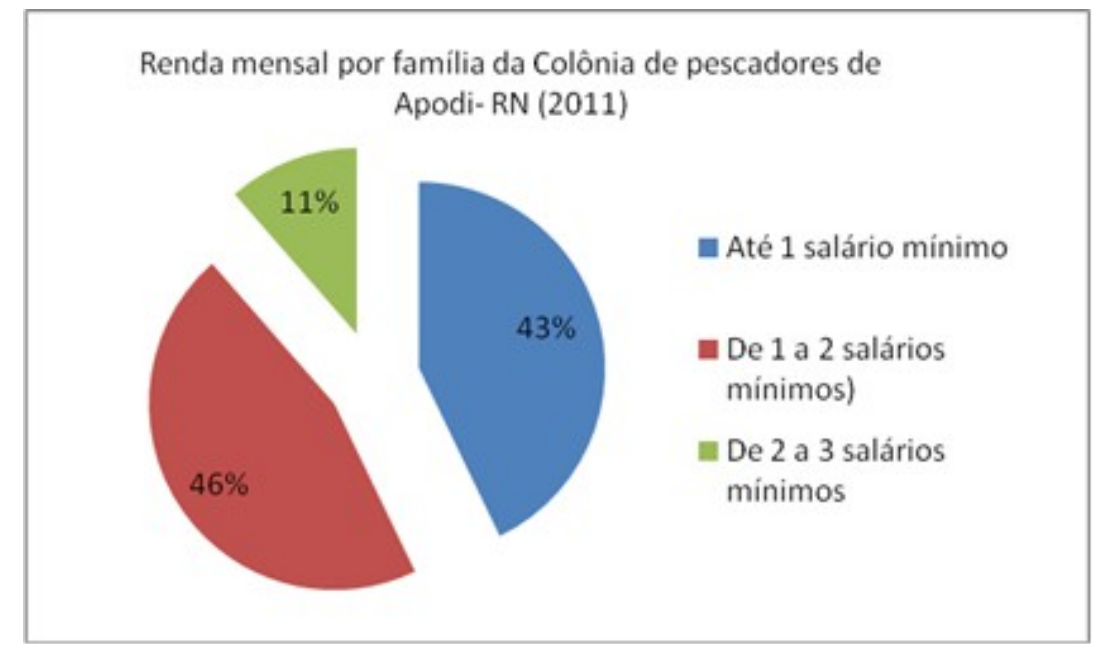

Figura 06: Gráfico da renda mensal por família das associações APAFA e AQUAPO.

Dos pescadores entrevistados, 43\% disseram receber até 1 (um) salário mínimo, tendo em vista que esses vivem apenas da pesca e da agricultura e como foi dito 
anteriormente, o lucro nas associações depende da produtividade e esta nem sempre é lucrativa. Alguns deles disseram ainda, ter uma renda fixa apenas no período de piracema, quando o Ministério do Trabalho paga o Seguro Defeso, que equivale a um salário mínimo por pessoa durante 2 a 3 meses. Cerca de $46 \%$ dos entrevistados ganham até 2(dois) salários mínimos, conciliando o lucro obtido da pesca com outras fontes de renda, principalmente atividades ligadas ao comércio e artesanato. Uma parcela mínima de $11 \%$ acumula de 2 (dois) a 3 (três) salários mínimos por mês, considerando o fato de que estas famílias abrigam indivíduos de idade avançada que dispõe de benefícios da previdência social e também se ocupam de outras funções. Essa informação nos permite apontar que a atividade pesqueira ainda representa uma contribuição pequena, mas significativa para a renda das famílias mensalmente, servindo também, como fonte de alimento.

Em relação ao número de pessoas por família, no núcleo pesquisado foi detectado que na maioria das residências o número considerado normal segundo os padrões nacionais, é de 3 a 4 pessoas por família, como pode ser observado no gráfico da figura 07, sendo que a outra parcela de 13 famílias, abriga um percentual de mais de 5 pessoas por domicílio. Isso ocorre, segundo relatos, devido ao fato de alguns filhos constituírem família e não terem autonomia para saírem de casa.

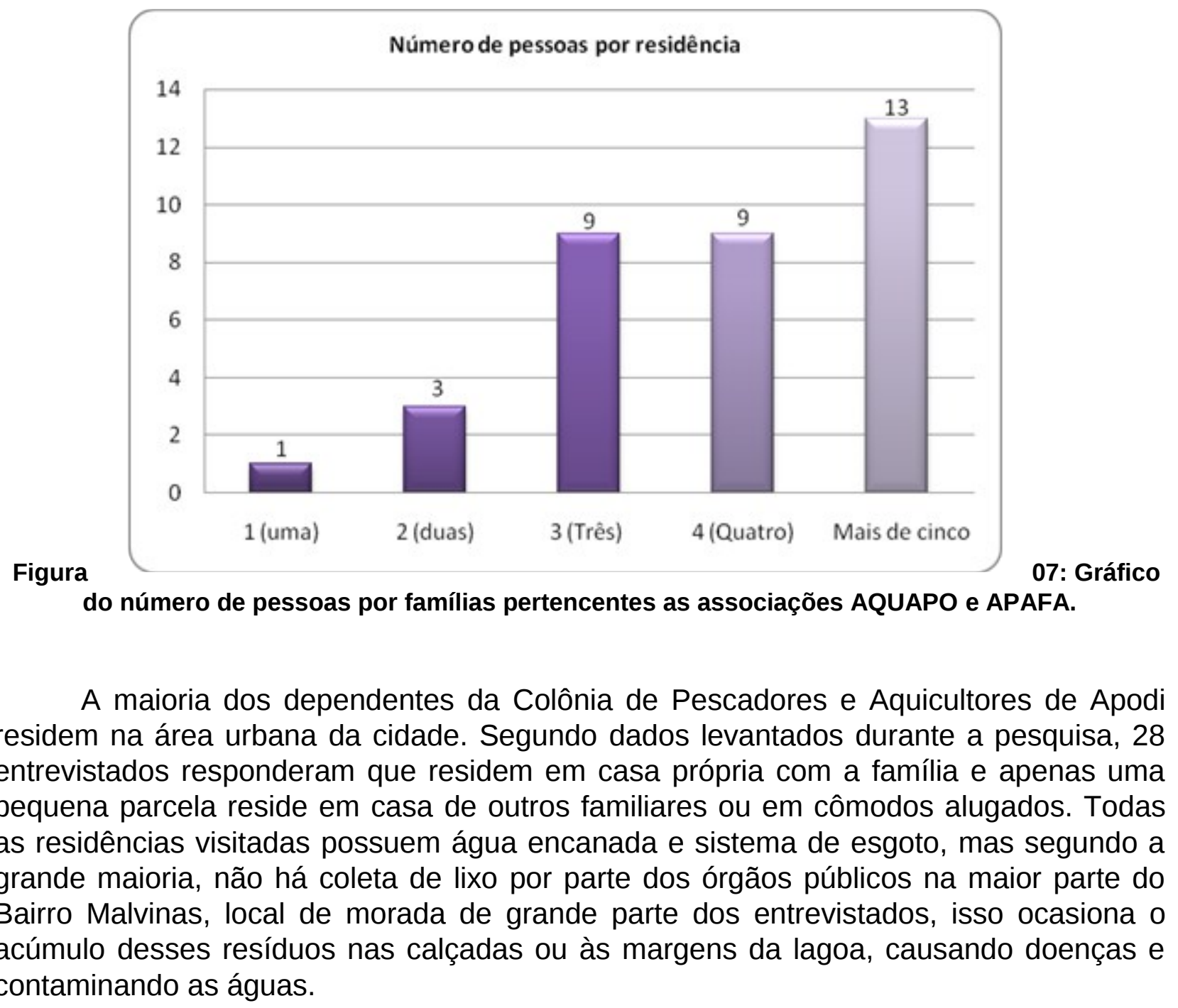


Segundo dados do IBGE (2010), em 2009 62,6\% dos domicílios brasileiros urbanos eram atendidos, ao mesmo tempo, por rede de abastecimento de água, redes coletoras de esgoto e coleta de lixo direta - em 1999, eram 57,2\%. Entre aqueles com rendimento médio de até $1 / 2$ salário mínimo per capita, o percentual não chegava à metade $(41,3 \%)$ e subia para $77,5 \%$ entre os domicílios com mais de dois salários mínimos de rendimento domiciliar per capita. Nesse mesmo ano, 21,1\% dos domicílios tinham simultaneamente energia elétrica, telefone fixo, internet, computador, geladeira, TV em cores e máquina de lavar (em 2004, eram 12,0\%). Na Região Nordeste a proporção era de $8,1 \%$.

Diante dos dados, pode-se dizer que a maioria dos entrevistados (30 pescadores) dispõe de aparelhos domésticos como geladeira, televisão, DVD, máquina de lavar e telefone móvel. Apesar de essa maioria ter acesso a esse tipo de utensílio doméstico, ainda há uma pequena, mas significativa parcela que não tem condições de manter esses tipos de aparelho.

O acesso a internet também é limitado para poucas famílias, sendo que 12 pessoas disseram ter acesso direto ou indireto a internet e 23 revelaram não ter acesso a este veículo de comunicação, o que revela um dado preocupante, visto que, diante da explosão tecnológica a qual estamos vivendo, é possível perceber que o acesso a estas inovações tecnológicas não chega a todos os espaços.

Referente à escolaridade dos pescadores, o nível foi considerado baixo, pois 6 entrevistados são analfabetos, 20 declararam ter apenas o ensino fundamental I, e muitos deles nem chegaram a concluir o ensino fundamental I. Já 9 pescadores chegaram até o ensino médio, mas apenas 3 concluíram. Isso se explica devido à grande necessidade que a maioria dos pescadores teve de trabalhar na infância, para complementar a renda da família, que também não dispunha de muitos recursos para manterem os filhos nas escolas (FIGURA 08).

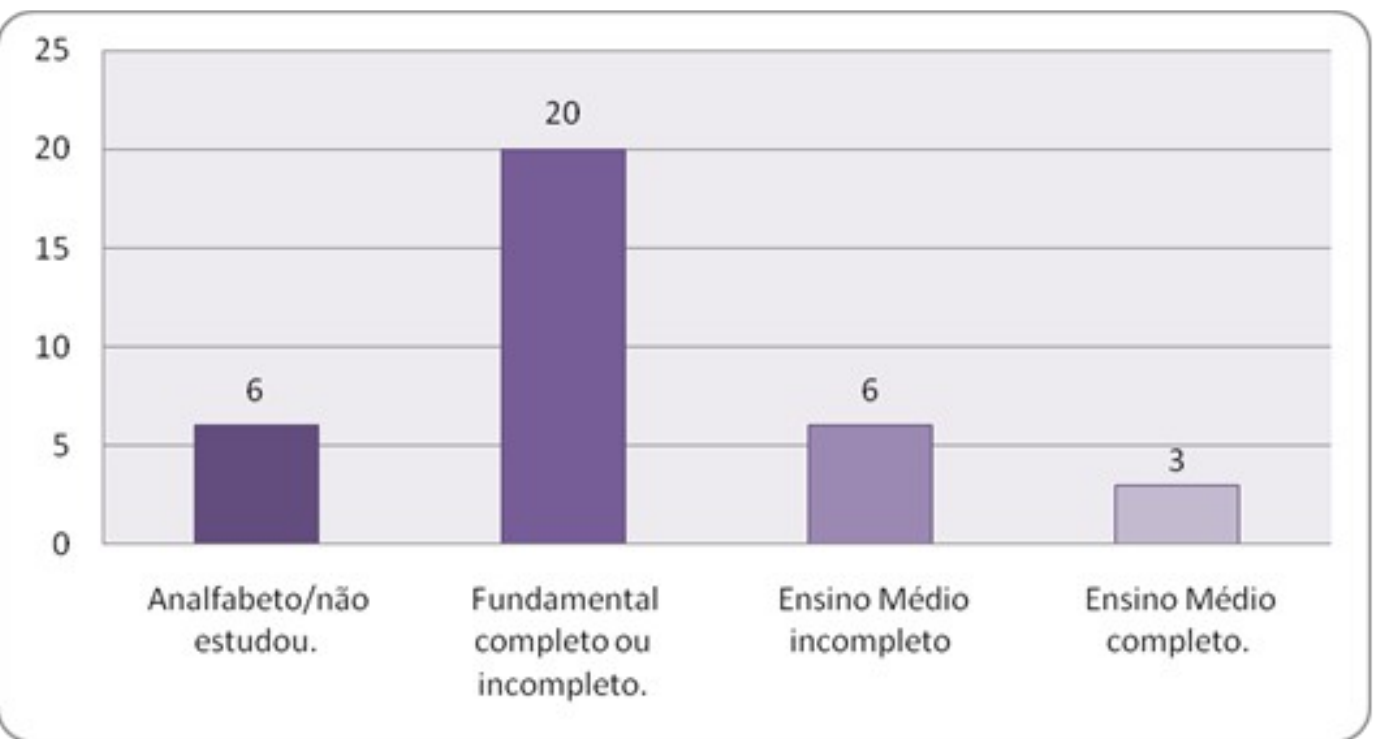

Figura

Gráfico do grau de escolaridade dos pescadores entrevistados na pesquisa. 
As reclamações mais frequentes dos pescadores durantes as entrevistas estavam alicerçadas ao fato de que alguns pescadores desrespeitarem o período de Piracema, pescando clandestinamente e os órgãos de fiscalização que deveriam estar alerta nesse período, não cumprem as visitas de rotina. Esses dados revelam o descaso do poder público com relação à preservação dos recursos naturais e do ecossistema local, ignorando o fato de que o ordenamento das atividades de pesca nesse período é importante para que a captura e criação do pescado seja feita de forma sustentável, preservando o ambiente, as espécies, e consequentemente, o futuro da atividade.

Nesse sentido, cabem às instituições que atuam na regulação e fiscalização do setor como IBAMA e SEAP, ampliar o espaço de suas atuações, inclusive com ações compartilhadas com a Prefeitura dos municípios vizinhos, as Colônias e Associações de Pescadores da região. O desrespeito por parte dos administradores em relação aos pescadores, também foi pautado durante as entrevistas. O desejo unânime dos 35 trabalhadores é de uma mudança na gestão e uma maior valorização e incentivo a classe, por parte da administração e dos órgãos públicos.

Outro dado preocupante é a assistência técnica para a pesca artesanal. Notou-se que atualmente a prática pesqueira na colônia está às margens de políticas de incentivo, vinculadas a pouca participação do Estado no que se refere a financiamento e auxílio técnico. Os resultados mostram que as duas associações recebem auxilio técnico da EMPARN, mas não têm a licença para usá-los.

Segundo os depoimentos colhidos, a licença para a implantação de novas gaiolas de criação depende da decisão do IBAMA, que alega ser essa uma agressão ao ecossistema aquático, devido às fezes liberadas pelos alevinos que com a implantação de novas gaiolas, ultrapassariam a quantidade permitida (FIGURA 09).

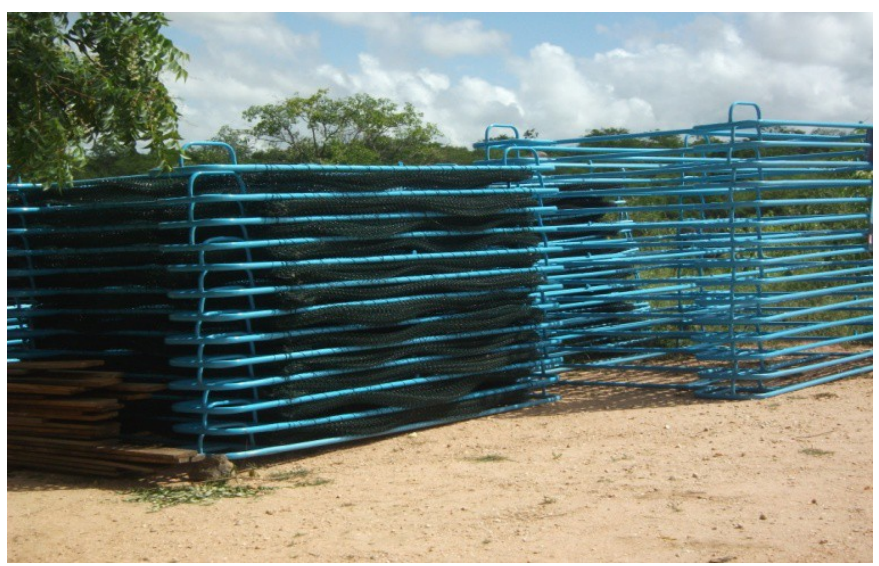

Figura 05: Gaiolas estocadas nas Associações por falta de licença para o uso.

Fonte: Vale, 2011.

Essa decisão interfere diretamente na vida do pescador, pois ocasiona o estoque e desgaste natural do material, além de impedir a ampliação da produção e o maior desenvolvimento do setor em escala local. Valendo salientar que apesar da deficiência encontrada no amparo técnico, a produção na colônia avança lentamente, mas de forma significativa com o decorrer dos anos. (Figura 05). 


\section{CONSIDERAÇÕES FINAIS}

A atividade pesqueira praticada no reservatório Santa Cruz não pode ser vista apenas como uma fonte de renda, mas sim como um importante meio de vida, que pode e deve ser conservado. É preciso lembrar que esta atividade é praticada por um pequeno grupo social que está ansioso para se capacitar, gerenciar e preservar a sua área de trabalho. Mas para que isso ocorra, algumas lacunas precisam ser preenchidas com urgência, tendo em vista a situação atual que os pescadores, suas famílias e as comunidades que sobrevivem da pesca artesanal, estão submetidas.

Diante dos dados colhidos e das observações de campo, concluiu-se que o nível de organização social dos pescadores precisa ser mais valorizado. Pois, apesar do município já possuir a Colônia de Pescadores, ainda há muitos conflitos internos que comprometem o andamento das atividades e consequentemente a vida do pescador. Outros dados que merece destaque são às atividades complementares realizadas pelos pescadores entrevistados, pois observou-se que estes praticam atividades simples e de pouco retorno de renda. E apenas da pesca, a sobrevivência se dá de maneira precária. O que reflete a falta de valorização e reconhecimento do governo e da sociedade para com essas populações e para com a prática pesqueira.

A eficácia dos serviços de assistência técnica também é um fator fundamental para ampliar o desempenho da pesca artesanal nas Associações de Pescadores do Município, visto que podem viabilizar uma melhor utilização e gestão dos fatores de produção e dos recursos naturais, garantindo melhores resultados para os dependentes e suas famílias. Para isso, é necessário que o Governo em todos os seus níveis, invista nessa categoria, ampliando a contribuição dos órgãos competentes e desenvolvendo políticas de incentivo a atividade pesqueira.

Todos os fatores analisados apontam para uma intensificação dos problemas sociais e econômicos vividos e percebidos pelos pescadores. Mas por outro lado, a permanência e persistência dos pescadores em darem continuidade à atividade pesqueira, mesmo em pequena escala, apontam para a necessidade de garantir o uso múltiplo dos recursos naturais do município. Embora com pouca visibilidade, presente nos pequenos espaços da cidade, a atividade pesqueira resiste e se mostra como uma das alternativas de reprodução social e como uma possibilidade de conciliar a geração de renda. Mas para isso é preciso a colaboração dos órgãos públicos para o desenvolvimento de projetos de extensão dessa atividade.

Espera-se que esse levantamento sirva como contribuição ao conhecimento da área, uma vez que a maior parte das pesquisas sobre a pesca e pescadores está voltada para as atividades litorâneas. Além disso, os dados podem possibilitar um futuro investimento em políticas de gestão que analisem os conflitos existentes no território pesqueiro, assim como o modo de vida da população, buscando incentivar essa atividade e reconhecer o pescador como sujeito social e principal personagem do modelo de gestão das pescarias. Dando-lhes meios de subsistência dignos e viáveis ao crescimento, principalmente aqueles das comunidades tradicionais que dependem 
exclusivamente do recurso, buscando a sustentabilidade de forma socialmente justa e ecologicamente viável.

\section{REFERÊNCIAS}

ACSELRAD, Henri. (2004). Conflitos ambientais: a atualidade do objeto. In ACSELRAD, Henri (org.). Conflitos ambientais no Brasil., Rio de Janeiro: Relume Dumará: Fundação Heinrich Boll, pp.7-11.

BRASIL. MINISTERIO DA PESCA E AQUICULTURA (2014). Boletim estatístico da pesca e aquicultura, 2010. Recuperado em 10 janeiro, 2014, de http://www.mpa.gov.br/images/Docs/Informacoes_e_Estatisticas/Boletim\%20Estat \%C3\%ADstico\%20MPA\%202010.pdf.

CARDOSO, E. S. (2007) Geografia e a questão pesqueira: tecendo redes de investigação. In: Biblio3W, Revista bibliográfica de Geografía y CienciasSociales, 07 (1), s.p.

CARDOSO, E. S.; FURLAN, M. C. MARTINS, J.; KEMEL, S. (2009, abril). Pesca e atividades complementares em águas interiores do Rio Grande do Sul. Anais do $12^{\circ}$ Encuentro de Geógrafos de América Latina, Montevideo.

CARDOSO, E.S. (2001) Geografia e pesca: aportes para um modelo de gestão. Revista do Departamento de Geografia. 14 (1), 79-88.

CIDREIRA NETO, I.R.G, RODRIGUES, G.G. (2017). Relação homem-natureza e os limites para o desenvolvimento sustentável. Revista Movimentos Sociais e Dinâmicas Espaciais. 6 (2), 142-156.

COSTA, T. V. (2003) O sol nasce para todos: leitura e interpretação do estatuto da Colônia de pescadores. 1 ed. Editora: Banco do Nordeste.

DIEGUES, A.C.S. (1983). Pescadores, camponeses e trabalhadores do mar (1a ed.). São Paulo: Ática.

DIEGUES, A.C.S. (1996). Ecologia humana e planejamento em áreas costeiras. SãoPaulo: NUPAUB-USP.

DIEGUES, A.C.S. (2000) Os saberes tradicionais e a biodiversidade no Brasil. São Paulo: NUPAUB - USP, 2000.

Empresa Brasileira de Pesquisa Agropecuária [EMBRAPA], (2017). Pesca e aquicultura. Palmas: Embrapa. Recuperado em 10 abril 2017, de https://www.embrapa.br/tema-pesca-e-aquicultural.

GONÇALVES, L.F (2006). Pesca: o mar como fonte de recursos em Cabo Frio. Rio de Janeiro: NEGEF.

INSTITUTO BRASILEIRO DE GEOGRAFIA E ESTATISTICA (2011). Síntese dos indicadores sociais. 2010. Recuperado em 10 março, 2011, de http://www.ibge.gov.br/home/estatistica/populacao/condicaodevida/indicadoresminim os/sinteseindicsociais2010.

INSTITUTO BRASILEIRO DE GEOGRAFIA E ESTATISTICA. (2009) Indicadores sociodemográficos e de saúde no Brasil. Recuperado em 10 março, 2011, de http://www.ibge.gov.br/home/estatistica/populacao/indic_sociosaude/2009.

Instituto UNIEMP (2011). Fórum permanente das relações UNIVERSIDADE - 
EMPRESA. Sustentabilidade da pesca. Recuperado em 03 janeiro 2011, de http://www.inovacao.scielo.br/scielo.pPhp.

MINISTÉRIO DA PESCA E AQUICULTURA (2010b). Jornal do Pescador. Ano 1. $1^{\mathrm{a}}$ edição.

MINISTÉRIO DA PESCA E AQUICULTURA. (2010a). Pesca Artesanal. Recuperado em 10 dezembro 2010, de http://www.mpa.gov.br/\#pesca/pesca-artesanal.

MOREIRA, R. (2017) Uma ciência das práticas e saberes espaciais. Revista Tamoios, 13 (2), 26-43.

PINHEIRO, R. V. (2003) Análise de sustentabilidade da carcinocultura: caso da comunidade de Requenguela, no município de Icapuí - Ceará. Dissertação de Mestrado, Universidade Federal do Ceará, Fortaleza, CE, Brasil.

QUEIROZ J. F. MOURA E. V. (1996). Aquacultura e recursos pesqueiros: alternativa para o desenvolvimento sócio-econômico do Rio Grande do Norte. Caderno de Ciência \& Tecnologia, 13 (2), 195- 224.

SALES, R. R. (2007). Limites e possibilidades na gestão da pesca artesanal costeira. In: LOBO, A. Nas redes da pesca artesanal. Brasília: IBAMA.

SANTOS, M. (2008). Espaço e método. São Paulo: Editora da Universidade de São Paulo.

SANTOS, M.A.S. (2005). A cadeia produtiva da pesca artesanal no Estado do Pará: estudo de caso no nordeste paraense. Amazônia Companhia e Desenvolvimento, 1 (1), $61-81$.

Secretaria de Estado da Pesca e da Agricultura do Estado do Pará - SEPAQ. (2010). Sobre pesca artesanal. Recuperado em 10 fevereiro 2011, de http://www.sepaq.pa.gov.br/index.php?q=node/24.

Secretaria Especial de Aquicultura e Pesca/ Presidência da República SEAP (2004). Instrução Normativa número 3, de 12 de maio de 2004. Diário Oficial da União de 13/05/2004, pág6. Dispõe sobre Operacionalização do Registro Geral de Pesca.

SILVA, A. F. (2009) Pesca artesanal: seu significado cultural. Ateliê Geográfico, 1 (6), 119-136.

SILVA, L. G. S. (1991). Pescadores, militares e burgueses: legislação pesqueira e cultura marítima no Brasil (1840-1930). Dissertação de Mestrado, Universidade Federal de Pernambuco, Recife, PE, Brasil. 